\title{
The impact of phonological neighborhood density on typical and atypical emerging lexicons* - ERRATUM
}

\author{
STEPHANIE L. STOKES
}

doi:ro.roiz/So3050009izoooroX, Published online by Cambridge University Press, 25 September 20I3.

There was an error made in the name of the author of this paper (Stokes 20I3). The author's name should have appeared as 'Stephanie F. Stokes'. The Press apologises for this mistake and any inconvenience it may have caused.

\section{R E F E R E N C E}

Stokes, S. L. (2013) The impact of phonological neighborhood density on typical and atypical emerging lexicons. Fournal of Child Language. Published online 25 September 2013, doi:10.1017/So30500091300010X. 